\title{
Review of Individual Health Insurance Policies for Mental Health Conditions
}

\author{
Kartik Singhai ${ }^{1}$, Thanapal Sivakumar ${ }^{2} \odot$, Hareesh Angothu $^{3}$, Deepak Jayarajan ${ }^{4}$
}

\begin{abstract}
In India, $85 \%$ of healthcare occurs in the private sector. Health insurance schemes can help prevent catastrophic health expenditure and resultant "poverty trap." Section 21 (4) of the Mental Health Care Act (MHCA) 2017 asks insurers to make provisions for treating mental illness on the same basis as is available for the treatment of physical illness. The Insurance Regulatory and Development Authority of India has required health insurance companies to comply with MHCA 2017. This paper discusses various health insurance policies available for mental health conditions and implications of a recent Delhi high court verdict for health insurance for mental illness.

Keywords: Autism spectrum disorder, Health insurance, India, Intellectual disability, Mental illness.

Indian Journal of Private Psychiatry (2021): 10.5005/jp-journals-10067-0076
\end{abstract}

\section{INTRODUCTION}

Worldwide, healthcare expenditures impose a substantial burden on the individual and the Government. ${ }^{1-3}$ The healthcare system varies across countries from complete Government health coverage to fully privatized healthcare systems. The United Kingdom delivers healthcare to its citizens through the Government's National Health Services funded by taxes. Other developed countries, such as Germany, France, and Australia, also provide near $100 \%$ healthcare coverage to their population. ${ }^{4}$ On the contrary, the United States of America is primarily an insurance-based healthcare system where healthcare access is based on the insurance policy purchased by the citizen, their family, or their employer. ${ }^{4}$

In most low- and middle-income countries, a significant proportion of healthcare expenditure is borne by the individual and family out-of-pocket. Ideally, the Government should bear the healthcare expenses of its citizens. ${ }^{5}$ The World Health Organization estimates that out-of-pocket expenditure on health in India is as high as $65.1 \%$ (percentage of the current health expenditure) compared to the world average of $32 \%{ }^{6}$ Every year, $3.5 \%$ of the Indian population becomes impoverished and 5\% face catastrophic expenditure due to medical bills. ${ }^{7}$ Assessment of the economic cost of the care for a person with a mental illness showed that the median out-of-pocket expenditure per month was approximately ₹1,000-1,500 (\$13.66-20.48). ${ }^{8}$ Healthcare expenditure is a huge burden, particularly for those belonging to the lower socioeconomic strata. Based on the level of infrastructure and care provided, the public healthcare system in India is organized as primary, secondary, and tertiary level care centers spread across more than 600 districts. Though healthcare is free in many publicly funded hospitals, $85 \%$ of medical care occurs in the private sector. ${ }^{8}$ Health insurance schemes can help prevent catastrophic health expenditure and resultant "poverty trap" does not reach every citizen. However, the concept favors those who can afford to buy a health insurance policy, unless policies are offered at highly subsidized rates by the Government.

\footnotetext{
${ }^{1-4}$ Department of Psychiatry, National Institute of Mental Health and Neurosciences, Bengaluru, Karnataka, India
}

Corresponding Author: Thanapal Sivakumar, Department of Psychiatry, National Institute of Mental Health and Neurosciences, Bengaluru, Karnataka, India, Phone: +91 080 26995834, e-mail: drt.sivakumar@yahoo.co.in

How to cite this article: Singhai $\mathrm{K}$, Sivakumar $\mathrm{T}$, Angothu $\mathrm{H}$, et al. Review of Individual Health Insurance Policies for Mental Health Conditions. Ind J Priv Psychiatry 2021;15(1):3-9.

Source of support: Nil

Conflict of interest: None

\section{Health Insurance}

Insurance is a contract between the insurance company and the policyholder in which an individual or entity receives financial protection or reimbursement against specified potential future losses from an insurance company. ${ }^{9}$

Health insurance works on the principle of risk pooling. It balances cost across a large, random sample of individuals. For example, an insurance company has a pool of 1,000 subscribers, each paying $₹ 1,000$ per year. In a year, 50 people out of 1,000 may get hospitalized for illness while the others stay healthy, which allows the insurance company to use money from the larger pool to treat people who become ill and make a profit.

The registration of Indian insurance companies regulations 2000 defines health insurance or health cover "as the effecting of contracts that provide sickness benefits or medical, surgical or hospital expense benefits, whether inpatient or outpatient, on an indemnity, reimbursement, services, prepaid hospital, or other plan bases, including assured benefits and long-term care."10

The market currently offers a range of health insurance schemes, which differ. Some significant ways they differ in are inclusion and exclusion criteria; health conditions covered; the network of hospitals; cashless treatment/co-payment clauses; and individual/group health insurance policies. The premium paid also differs according to the

(c) The Author(s). 2021 Open Access This article is distributed under the terms of the Creative Commons Attribution 4.0 International License (https://creativecommons. org/licenses/by-nc/4.0/), which permits unrestricted use, distribution, and non-commercial reproduction in any medium, provided you give appropriate credit to the original author(s) and the source, provide a link to the Creative Commons license, and indicate if changes were made. The Creative Commons Public Domain Dedication waiver (http://creativecommons.org/publicdomain/zero/1.0/) applies to the data made available in this article, unless otherwise stated. 
following factors: age, medical history, risky behavior (including substance use), and no claim discounts for previous years. ${ }^{7}$

The article covers individual health insurance schemes (public and private) that provide coverage to mental health conditions (including developmental disabilities and mental illness), which were available as of June 2021. The article excludes group policies (like central Government health scheme, employees' state insurance scheme for employees, Rashtriya swasthya bima yojana for unrecognized sector workers and their families below the poverty line (BPL), state employees group insurance, and defense services health insurance).

\section{Publicly Funded Health Insurance Policies Covering Mental Illness and Developmental Disabilities}

The Niramaya Health Insurance Scheme was launched by the National Trust (NT) under the Government of India on March 26, 2008. ${ }^{11}$ The scheme provides insurance cover for persons with disabilities (PwD) covered by National Trust Act, 1999 (including cerebral palsy, autism, intellectual disability, and multiple disabilities). There is no age limit to avail of the scheme. The premium for NHIS is nominal, ranging from ₹ 50 to ₹ 500 per annum based on whether the PwD is below the poverty line (BPL) or not. Some State Governments, like Karnataka, pay the premium on behalf of PwD from BPL families. The sum insured is up to ₹1 lakh/-."1 More details are given in Table 1.

The Swavlamban Health Insurance Scheme, launched in October 2015 by the Government of India, was the first insurance policy for persons with mental illness and six other disabilities covered by the Persons with Disabilities Act 1995. ${ }^{7}$ PwD with an annual family income of ₹3 lakhs or below were eligible to avail of the scheme's benefits. A premium of ₹357 was collected from the insured person. The scheme also covered outpatient department (OPD) cover up to ₹3,000 per annum. The scheme was stopped in 2017.

In 2018, the Ayushman Bharat (National Health Package Scheme) was launched by the Government of India, targeting deprived families per the socioeconomic caste census data. ${ }^{12}$ The Pradhan Mantri Jan Arogya Yojana component provides cashless health insurance cover up to ₹ 5 lakh per family (no restriction of family size) per year. States/union territories (UTs) were advised to implement the scheme by a dedicated entity called the State Health Agency. Various states are implementing the Ayushman Bharat schemes under various names. For example, it is called "Arogya Karnataka" in the Karnataka state and includes packages to treat mental illnesses in Government hospitals. ${ }^{12}$ Biju Swasthya Kalyan
Yojna of the Odisha Government also covers expenses for treating mental illness in Government hospitals. ${ }^{13}$

A few states are implementing their health insurance schemes, namely Swasthya Sathi (Government of West Bengal), Aarogyashri (Government of Telangana), and Quality Health for all (Government of Delhi) but unfortunately, none of these mentions or includes coverage for mental illness. ${ }^{14}$

\section{Review of Insurance Policies Covering Autism Spectrum Disorder}

Two insurance companies are offering health coverage for persons with autism spectrum disorder. ${ }^{16}$ The details are mentioned in Table 2.

\section{Mental Health Care Act (MHCa) 2017 and Insurance Regulatory and Development Authority of India (IRDA) Circulars on Health Insurance for Persons with Mental Illness}

For about six decades after independence, Indian insurance companies excluded treatment expenses for mental illness in individual health insurance policies, possibly due to poor awareness about mental illness and a lack of advocacy.

The Mental Health Care Act (MHCA) 2017 was a landmark moment for insurance coverage of persons with mental illness. Section 21 (4) of MHCA 2017 states, "every insurer shall make provision for medical insurance for treatment of mental illness on the same basis as is available for the treatment of physical illness." ${ }^{\prime 5,19}$ According to Chapter 1 of MHCA 2017, mental illness "means a substantial disorder of thinking, mood, perception, orientation or memory that grossly impairs judgment, behavior, capacity to recognize reality or ability to meet the ordinary demands of life, and mental conditions associated with the abuse of alcohol and drugs, but does not include mental retardation that is a condition of arrested or incomplete development of mind of a person, specially characterized by subnormality of intelligence." ${ }^{19}$ This definition covers all mental illnesses under the F code of ICD-10 except intellectual disability.

After 1.5 years of passing the Act, the Insurance Regulatory and Development Authority of India (IRDAI) issued a circular on August 16,2018 , to include mental illness under the ambit of insurance coverage. ${ }^{20}$ On June 2, 2020, IRDAI issued a circular stating that insurance companies should comply with the provisions of MHCA

Table 1: Brief details on publicly funded health insurance policies available for subscription covering developmental disabilities

\begin{tabular}{|c|c|c|c|c|c|}
\hline SI. No. & Name of plan & Sum insured (₹) & Important inclusions & Important exclusions & $\begin{array}{l}\text { Other } \\
\text { remarks }\end{array}$ \\
\hline 1. & $\begin{array}{l}\text { Niramaya (health } \\
\text { insurance scheme) }\end{array}$ & $\begin{array}{l}1 \text { lakh } \\
\text { Sublimits }{ }^{15} \\
\text { - Hospitalization: } 70,000 \\
\text { - Outpatient department: } 14,500 \\
\text { - Ongoing therapies to reduce the impact of } \\
\text { disability and disability-related complications: } \\
10,000 \\
\text { - Alternative medicine: } 4,500 \\
\text { - Transportation costs: } 1,000\end{array}$ & $\begin{array}{l}\text { All PwD under the } \\
\text { National Trust Act, } 1999 \\
\text { with valid } \\
\text { disability certificate }\end{array}$ & $\begin{array}{l}\text { PwD not covered by } \\
\text { National Trust Act, } \\
1999\end{array}$ & - \\
\hline
\end{tabular}

Disclaimer: Information on individual policies to be referred to as in the policy document 
Table 2: Brief details on individual health insurance policies covering autism spectrum disorder ${ }^{17,18}$

\begin{tabular}{|c|c|c|c|c|c|}
\hline SI. No. & Name of plan & Sum insured (₹) & Important inclusions & Important exclusions & Waiting period \\
\hline 1. & $\begin{array}{l}\text { Star special } \\
\text { cover }\end{array}$ & 3 lakhs & $\begin{array}{l}\text { Persons with autism spectrum } \\
\text { disorder, aged 3- } 25 \text { years. } \\
\text { Covers behavioral therapy, } \\
\text { physiotherapy, occupational } \\
\text { therapy, and speech therapy on } \\
\text { OPD basis. }\end{array}$ & $\begin{array}{l}\text { Any hospital admission primarily for } \\
\text { investigation/diagnostic purposes, } \\
\text { substance abuse, and self-inflicted } \\
\text { injuries }\end{array}$ & $\begin{array}{l}\text { - } 24 \text { months waiting period for } \\
\text { specified disease/procedure } \\
\text { - } 48 \text { months waiting period } \\
\text { for treatment of preexisting } \\
\text { disease }\end{array}$ \\
\hline 2. & $\begin{array}{l}\text { Religare Care } \\
\text { Freedom } \\
\text { plan }\end{array}$ & 3-10 lakhs & $\begin{array}{l}\text { Covers autism along with other } \\
\text { illnesses; only policy to cover } \\
\text { persons with autism aged } \\
>25 \text { years }\end{array}$ & $\begin{array}{l}\text { Treatment of mental illness, stress, } \\
\text { or psychological disorders. } \\
\text { Any treatment taken in a clinic, } \\
\text { rest home, convalescent home for } \\
\text { the addicted, detoxification center, } \\
\text { sanatorium, home for the aged, } \\
\text { mentally disturbed, remodeling } \\
\text { clinic, or similar institutions }\end{array}$ & $\begin{array}{l}24 \text { months waiting period for } \\
\text { preexisting diseases. }\end{array}$ \\
\hline
\end{tabular}

Disclaimer: Information on individual policies to be referred to as in the policy document; certain areas where verified information could not be tracked have been intentionally left blank

2017 and should publish on their website the philosophy and approach about covering person affected with mental illness and that the compliance should be in place by October 1, 2020. ${ }^{21}$

\section{Review of Insurance Policies Covering Mental Illness}

Few insurance companies have started covering mental illness over the last few months after the IRDA circulars.

The following issues need to be considered regarding health insurance policies for persons with mental illness (Table 3).

- This is a new area for most insurance companies, and hence some confusion is likely in the implementation.

- Lack of data on the number of people with mental illness requiring inpatient care and insufficient data on the average duration of admission for a specified diagnosis could become a barrier to private insurance companies rolling out policies during the next few years.

- Public sector health insurers still have mental illness under the exclusion list and are not offering coverage. For instance, the United India Insurance Company and the New India Assurance Company mention psychiatric and psychosomatic disorders in the exclusion list. ${ }^{22}$

- Most policies will cover costs incurred due to hospitalization related to mental illness. OPD treatment is generally not covered unless specifically mentioned. Further, in OPD cover, claims are settled mainly by reimbursement with the cashless benefit not being given. ${ }^{22}$ Some plans may cover preexisting conditions while some may not.

- A further limited number of plans may be available for severe mental illness.

Here, we present brief details on specific health insurance policies provided by private companies. Insurance policies that include cover for any mental illness are included with notable inclusions/exclusions we could find in their policy document.

\section{Critical Evaluation of Available Health Insurance Policies Covering Mental Illness}

The IRDAI master circular on standardization of health insurance products (2020) states explicitly that no health insurance policy shall incorporate the following exclusions in terms and conditions of the policy: treatment of mental illness, stress, and psychological disorders and neurodegenerative disorders; behavioral and neurodevelopmental disorders, including disorders of adult personality; and disorders of speech and language, including stammering and dyslexia. ${ }^{27}$ The available health insurance policies have excluded some of these conditions in violation of the IRDAI master circular.

The MHCA 2017 definition of mental illness includes "mental conditions associated with the abuse of alcohol and drugs." ${ }^{19}$ None of the health insurance policies follow the comprehensive MHCA definition of mental illness and exclude substance use-related disorders. IRDAI master circular on standardization of health insurance products (2020) permits exclusion of "treatment for alcoholism, drug or substance abuse or any addictive condition and consequences thereof" from health insurance coverage in violation of MHCA 2017. This exclusion is discriminatory and leaves the circular in direct contradiction of the Act, both in letter and spirit.

A key feature of MHCA 2017 was the decriminalization of suicide and presumption of severe stress in any person who attempts to commit suicide. ${ }^{19}$ The Government also has a duty to provide "care, treatment, and rehabilitation" to the person who attempted suicide. ${ }^{19}$ Unfortunately, self-inflicted injuries and suicide attempts are not covered by the available health insurance policies.

Health insurance coverage for mental illness needs to be on par with physical illness. There seems to be resistance within the health insurance sector to realize this parity in their policies. For example, available health insurance policies do not cover mental illness or have separate caps for mental illness treatment expense and limit the number of OPD visits covered or have a more extended waiting period to cover preexisting mental illness. ${ }^{19}$ Health insurance companies can be prosecuted under section 109 of MHCA 2017 for not following section 21(4) of MHCA 2017.

Though outpatient care accounts for a substantial proportion of mental health services, it is not covered by all health insurance policies.

\section{Recent Court Cases Regarding Health Insurance Policies for Persons With Mental Illness}

A recently concluded landmark case (Shikha Nischal vs National Insurance Company Ltd (NICL) and ANR) provides much-needed 


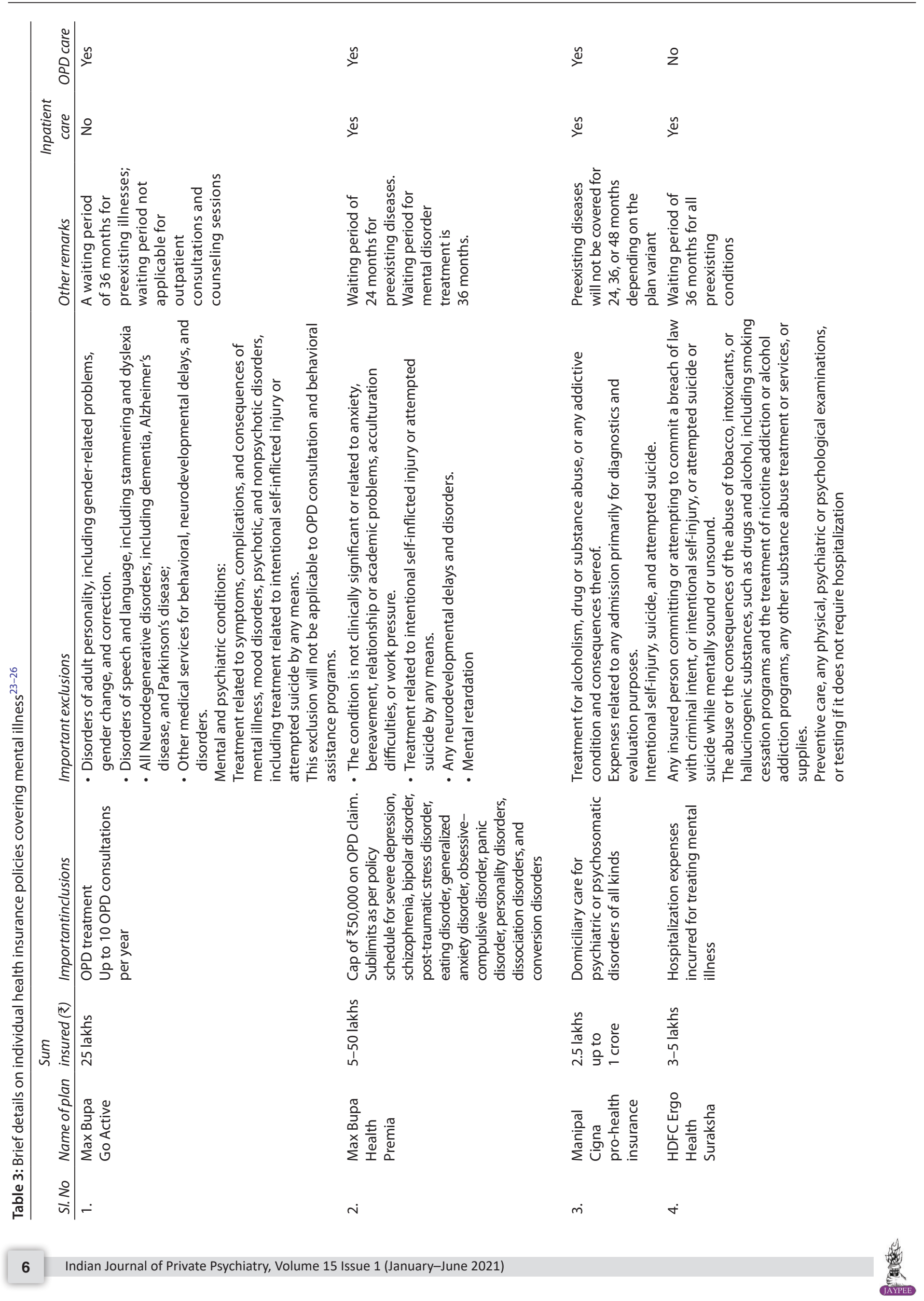




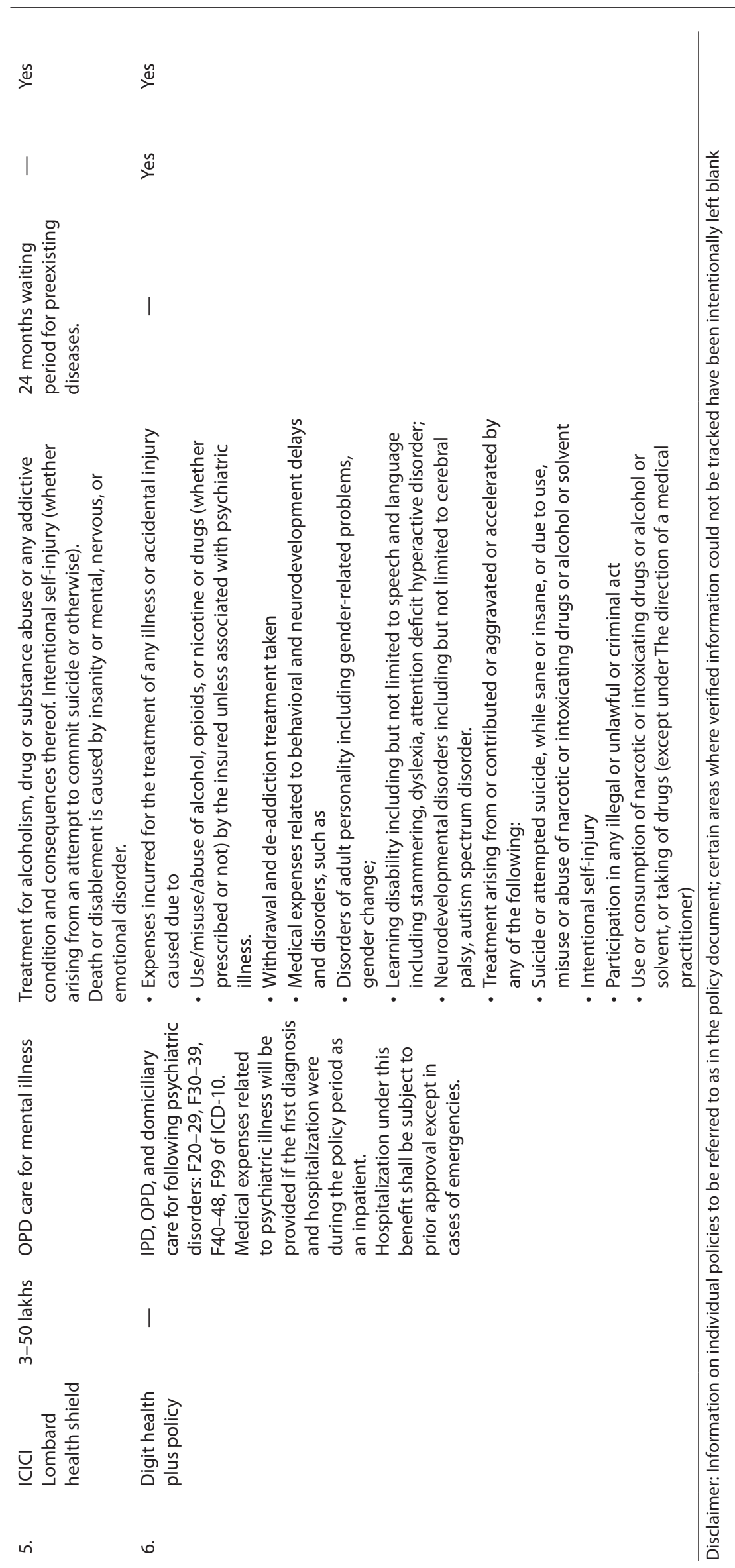


direction in this area. ${ }^{28}$ In this case, the petitioner had taken a health insurance policy for a total sum of ₹3,95,000. In June 2020, the petitioner obtained inpatient care for schizoaffective disorder and incurred expenses of ₹5,54,636. The petitioner then applied for reimbursement of treatment expenses from NICL as per Clause 1.1 of the Healthcare Policy. Her claim was rejected based on the exclusion policy of the insurance stating that psychiatric disorders were excluded from the cover. She then filed a complaint before the insurance ombudsman, relying upon the provisions of MHCA, 2017. However, the insurance ombudsman observed that the petitioner's claim would have to be settled as per the terms and conditions of the policy and rejected the petitioner's claims. Subsequently, she filed a petition in Delhi high court that such rejection would violate MHCA 2017. During the case's proceedings, after the hearing of March 18, 2021, the IRDAI directed the NICL to pay the petitioner's claim. Accordingly, the maximum coverage of the healthcare policy of ₹3,95,000 (the entire sum insured) was paid to the petitioner. The Delhi high court then, in its judgment, clearly says that "mental illnesses can be treated no differently from physical illnesses. Insurance policies also cannot discriminate between these two types of illnesses. The reasons for the nondiscriminatory provisions between mental and physical illnesses are not far to seek." Since the petitioner had to resort to litigation for the claim to be honored, the Delhi high court ordered NICL to pay another ₹25,000 as costs to the petitioner.

In another critical ongoing case (Subhash Khandelwal vs Max Bupa Health Insurance Company), the Delhi high court has questioned the IRDAI to explain the basis of approving insurance policies that exclude mental conditions from full coverage. ${ }^{29}$ The case is against Max Bupa Insurance Company, wherein the petitioner has claimed that he has been regularly paying the premium for a sum assured of ₹35 lakhs, but when claimed for the treatment and perusing the fine print, it appeared that almost all prevalent mental health conditions were capped at a sum limited to ₹50,000. The case is yet ongoing when writing this article, with the current status being the Delhi high court awaiting the response from IRDAI and Max Bupa on the basis for excluding mental illnesses from full coverage.

These cases put forth the importance of activism and selfadvocacy-as well as appropriate jurisprudence-to provide the much-needed impetus to align insurance policies with the progressive requirements of MHCA 2017. The case of Shikha Nischal vs NICL reflects how the legal intervention was necessary to claim the health insurance rights for a person with mental illness. The court also observed that the IRDAl's lack of monitoring over insurance companies was a dereliction of its statutory duty to fully supervise and ensure that all the insurance companies implemented Section 21 (4) of MHCA 2017.

\section{Role of Mental Health Professionals}

While recent court verdicts should hopefully pressure the IRDAI and health insurance companies to correct anomalies, mental health professionals, and professional bodies need to take a more proactive role and enhance awareness among persons with mental illness on recent developments. Professional bodies can create task forces to highlight ambiguities in current health insurance policies, ensure implementation of the law, and lobby for an increase in public spending for mental health services to bridge the treatment gap. Various stakeholders, including mental health professionals,
PwD, persons with mental illness, and families of persons with mental illness, need to work collectively. ${ }^{30}$

The Government of India should aim to provide universal health coverage including mental health services at par with countries, like the United Kingdom. The Government should decentralize mental health services and make communitybased services available for the treatment of mental illness. The Government can also consider coming up with subsidized health insurance policies, like erstwhile "Swavlamban health insurance scheme for PwD" [as per clause 24 (3j) of the Rights of Persons with Disabilities Act, 2016]. This will cover persons disabled with mental illness. All policy measures will combat the issues related to stigma toward mental health, mental health literacy, and access to mental healthcare.

\section{Conclusion}

The article has summarized the status of individual health insurance policies covering mental illness in India as of June 2021. Though there is encouraging movement in this direction, a lot remains to be done. This is essential since most insurance policies cater to the population, which can afford to buy them. Thus, insurance cover provides a short-term plan for health expenditure. Comprehensive universal health coverage is the need of the hour.

\section{OrCID}

Thanapal Sivakumar $\odot$ https://orcid.org/0000-0002-9498-9424

\section{References}

1. Selvaraj S, Farooqui $\mathrm{HH}$, Karan A. Quantifying the financial burden of households' out-of-pocket payments on medicines in India: a repeated cross-sectional analysis of National Sample Survey data, 1994-2014. BMJ Open 2018;8(5). DOI: 10.1136/bmjopen-2017-018020.

2. Branning $G$, Vater $M$. Healthcare spending: plenty of blame to go around. Am Health Drug Benefits 2016;9(8):445-447.

3. Gupta A, Reddy BV, Semwal V, et al. Financial burden of out-of-pocket expenditures for primary health care in hilly areas of Garhwal Region, Uttarakhand, North India. J Clin Diagn Res JCDR 2017;11(4):LC08-LC11. DOI: 10.7860/JCDR/2017/24761.9646.

4. Papanicolas I, Mossialos E, Gundersen A, et al. Performance of UK National Health Service compared with other high income countries: observational study. BMJ 2019;367:I6326. DOI: 10.1136/ bmj.16326.

5. Jagadish A, Ali F, Gowda MR. Mental healthcare act 2017 - the way ahead: opportunities and challenges. Indian J Psychol Med 2019;41(2):113-118. DOI: 10.4103/IJPSYM.IJPSYM_38_19.

6. Vardell E. Global health observatory data repository. Med Ref Serv Q 2020;39(1):67-74. DOI: 10.1080/02763869.2019.1693231.

7. James JW, Basavarajappa C, Sivakumar T, et al. Swavlamban Health Insurance scheme for persons with disabilities: An experiential account. Indian J Psychiatry 2019;61(4):369. DOI: 10.4103/psychiatry. IndianJPsychiatry_77_19.

8. Gururaj G, Varghese M, Benegal V, et al. National Mental Health Survey of India, 2015-16: prevalence, patterns and outcomes. Bengaluru: National Institute of Mental Health and Neuro Sciences, NIMHANS Publication No. 129; 2016.

9. Sivakumar T, Jw James, Basavarajappa C. Health insurance schemes for children and adolescents with psychiatric disability. J Indian Assoc Child Adolesc Ment Health - ISSN 0973-1342 2017;13(1):1-9.

10. Mohandoss AA, Thavarajah R. An audit of Indian Health Insurance claims for mental illness from pooled insurance information Bureau's Macroindicator Data. Indian J Psychol Med 2017;39(3):254-261. DOI: 10.4103/0253-7176.207340. 
11. Angothu H, Muliyala KP. Why should Indian pediatricians be aware of the Niramaya Health Insurance Scheme? Indian J Pediatr 2021;88(1):87. DOI: 10.1007/s12098-020-03395-9.

12. Bijal AS, Kumar CN, Manjunatha N, et al. Health insurance and mental illness. Indian J Psychiatry 2019;61(10):791-797. DOI: 10.4103/ psychiatry.IndianJPsychiatry_158_19.

13. Biju Swasthya Kalyan Yojana|Govt. of Odisha. Available from: http:// www.nhmodisha.gov.in/frmrbsyostfbkky.aspx [Last accessed May 31, 2021].

14. Singh OP. Insurance for mental illness: government schemes must show the way. Indian J Psychiatry 2019;61(2):113. DOI: 10.4103/ psychiatry.IndianJPsychiatry_127_19.

15. NIRAMAYA Ministry of Social Justice and Empowerment (MSJE) [cited May 7, 2021]. Available from: https://www.thenationaltrust.gov.in/ content/scheme/niramaya.php.

16. For autism treatment, insurance an issue. Livemint; April 6, 2019. Available from: https://www.livemint.com/insurance/news/forautism-treatment-insurance-an-issue-1554527294789.html.

17. Star Special Care [cited May 9, 2021]. Available from: https://www. starhealth.in/health-insurance-for-autism-kids.

18. Care Health Insurance (Religare Health Insurance Company)—buy online health insurance [cited May 9, 2021]. Available from: https:// www.religare.com/Health-Insurance.aspx.

19. Mental Health Care Act 2017 No.V.15011/09/2017-PH-1; September 20, 2017. Available from: https://main.mohfw.gov.in/sites/default/ files/Final\%20Draft\%20Rules\%20MHC\%20Act\%2C\%202017\% 20\%281\%29.pdf.

20. IRDAI circular IRDA/HLT/MISC/CIR/128/08/2018 dated August 16, 2018 on The Mental Healthcare Act, 2017. Available from: https:// www.irdai.gov.in/admincms/cms/whatsNew_Layout.aspx? page $=$ PageNo3555\&flag $=1$ [Last accessed May 31, 2021].

21. IRDAI circular IRDAI/HLT/MISC/CIR/129/06/2020 dated June 2, 2020 on Disclosure of underwriting philosophy of offering Insurance coverage to Persons with Disability (PWD) and people affected with HIV/AIDS and mental illness diseases. Available from: https://www.irdai.gov.in/ admincms $/ \mathrm{cms} /$ whatsNew_Layout.aspx?page $=$ PageNo4140\&flag $=1$ [Last accessed May 31 2021].
22. Nirmal R. Is mental illness cover worth the money? Businessline [cited May 15, 2021]. Available from: https://www.thehindubusinessline. com/portfolio/personal-finance/is-mental-illness-cover-worth-themoney/article33644591.ece.

23. Max Bupa launches 'GoActive': a digitally enabled 'Everyday Use' health insurance plan to keep Indians financially and physically fit [cited May 9, 2021]. Available from: https://www.maxbupa.com/ press-release/max-bupa-launches-goactive-a-digitally-enabledeveryday-use-health-insurance.html.

24. ManipalCigna Prohealth Insurance with Comprehensive Hospitalization Coverage [cited May 9, 2021]. Available from: https://www.manipalcigna. com/hospitalization-cover/prohealth-insurance.

25. Health Insurance Policy online in India: go digit general insurance. Digit insurance [cited May 9, 2021]. Available from: https://www. godigit.com/content/godigit/directportal/en/campaigns/healthinsurance.html.

26. Family Health Insurance Plans - buy health insurance for family online - ICICl Lombard [cited May 9, 2021]. Available from: https:// www.icicilombard.com/health-insurance/complete-healthinsurance?opt=chi\&source=nav.

27. IRDAI circular IRDAI/HLT/REG/CIR/193/07/2020 dated Jul 22, 2020. Available from: https://www.irdai.gov.in/ADMINCMS/cms/ frmGuidelines_Layout.aspx?page=PageNo4196\&flag $=1$.

28. Shikha Nischal V. National Insurance Company Limited and ANR [cited May 9, 2021]. Available from: https://www.legitquest.com/ case/shikha-nischal-v-national-insurance-company-limitedanr/1E717A.

29. Explain basis for approving insurance policies excluding mental illnesses from full coverage: HC to IRDA. The Hindu; April 18, 2021 [cited 2021 May 15]. Available from: https://www.thehindu. $\mathrm{com} /$ news/cities/Delhi/explain-basis-for-approving-insurancepolicies-excluding-mental-illnesses-from-full-coverage-hc-to-irda/ article34349773.ece.

30. Seshadri K, Sivakumar T, Jagannathan A. The family support movement and Schizophrenia in India. Curr Psychiatry Rep 2019;21(10):95. DOI: 10.1007/s11920-019-1081-5. 